\title{
DESIGNING A FIVE STAR HOTEL WITH THE APPROACH OF SUSTAINABLE ARCHITECTURE IN BANDAR ABBAS
}

\author{
Samira Alidadi \\ M.A student at Islamic Azad University of Bandar Abbas, Bandar Abbas, North Golshahr, Saadat Alley, \\ Bahman street \\ Samiraalidadi1393@gmail.com \\ Zeynab Yousefi Zadeh \\ University instructor, at Bandar Abbas Azad University
}

\begin{abstract}
Hotel is a service complex with the aim of earning revenue and the profit is a formatted phenomenon history of which is backed to industrial revolution of Europe. Today, tourism is not only belongs to wealthy families; it also belongs to millions of people who visit new places. Even though new era of tourism has started and proceeded, many exogenous factors affect it. The importance of proper tourism resort numbers in Bandar Abbas caused more attention toward designing a five star hotel there. It's because Bandar Abbas is one of the most important centers for Central Asia and there are lots of historical, natural and cultural attraction but there's not enough resorts there. This study is conducted by analytical-descriptive method with the pivot of sustainable architecture (green architecture) in a hotel. The data are collected by a library method. The results show that the sustainable tourism can provide guidelines for accessing to a stable development in tourism and using the sustainable energy is emphasized. The concept of sustainable development is an important change in understanding the relationship between humans, their communications and nature. Therefore, the aim of the present research is designing a hotel obtaining practical needs beside its aesthetic aspects.
\end{abstract}

Keywords: 5 star hotel, sustainable architecture, resorts, sustainable energy

\section{INTRODUCTION}

Tourism is considered as one of the most vast and varied industry in the world. Many countries consider it as the main source of income, employment and growth of the private section and infrastructure development. Specially, the tourism industry is attracted by developing countries where other economic developments such as production or natural resource extraction are not economic or they do not have an important role in commerce and trade domain.

People travel with different and complex reasons. Increasing growth of tourism shortly caused that some factors which play important role in this area to be taken into consideration. Many people around the world who never expect the traveling can financially afford it. Building motels and recreation resorts in different areas turned to be one of the most dominant budgets in big cities. They all are tending to build motels and resorts around airports and villages. Services delivered by tourism agencies, travel operators, tourism offices and finally technologies led the travelers have safe and exciting travels.

Totally, the tourism industry has been one of the most important factors in recent decades which linked different cultures. The result of this linkage has been the cultural communication. Iranian culture with its thousand year's history has been the center of science and literature, art and culture. It has also been attracted by people from far and near countries and it has been the host of many tourists for a long time. 
In recent century, it's the target of many tourists around the world with different purposes such as curiosity, gaining knowledge and exploration.

Hereon, Bandar Abbas city is special. It recalls us the cultural gentility by mentioning a brilliant history and amazing arts. The thousand year's old history of this city and existence of beautiful historical places such as the sea, traditional bathrooms, mosques, crafts, various industries and agricultural production made it to be the destination of many tourists. In the present research, designing a resort complex is one of the steps that can attract tourists and tourism industry development. Specially, designing this complex can meet the research economic and cultural goals if it would be conducted in Bandar Abbas based on the present statistics in tourism industry and potential facilities.

\section{STATEMENT OF THE PROBLEM}

In a world that we live in, different cultures and civilizations become smaller by communication. The third millennium is a step toward tourism which is one of the most important industries around the world. Fast growth of tourist also affected Iran. The country's decision makers have concerned about it because tourism attraction affects the economical profit. Such tourist attractions, the civilization and culture of Iran led the idea of dialogue among civilizations in a way that the ideal was called so by Iran's suggestion in 2001. However, due to the lack of a comprehensive and principal planning, facilities and proper advertisement, tourist's problems in Iran led to the cultural and religion differences, low quality of resorts, lack of modern transportation and etc. this industry is not progressed yet. It should not be forgotten that the art, literature and hospitality of Iranian people, the existence of historical places from different civilizations and special style of Iranian and Islamic architecture are the other attractions. By analyzing such factors, it can be concluded that the upcoming progress of tourism and people's attraction to it, providing facilities to accept these travelers should be considered both qualitatively and quantitatively. It should be also regarded in country's massive planning. The importance of building international hotels and resorts can be analyzed from some perspectives:

First of all, the idea of dialogue among civilizations should be taken into consideration. Building a relationship between different cultures and the possibility of meeting other cultures and identifying new knowledge and western massive developments in all areas are the purpose of this idea. The economic aspect is the other factor. According to some official suggestions, the tourism industry can create 500,000 job opportunities annually and 7.5 milliard dollar would be the revenue of the country for a single year. Moreover, 8 job opportunities would be possible by the entrance of a tourist. Bandar Abbas and its tourism attraction increases the need of creating the resort complexes. Its architecture analysis and can help designing such places because the key of every success is in human's understanding, analyzing and performance. In this study, it's tried to make Bandar Abbas as a proper place for Iranian and foreigner tourists by using unique properties of Iranian architecture.

\section{AIM}

The present study analyzed the 5 star hotel design by sustainable architecture approach.

\section{METHODOLOGY}

Since the subject of the research is designing a 5 star hotel which is built on tourism industry i.e. a domain in architecture and city building on social and human science, it's somehow complex. It means, we used some methods that can complete each other. We also used library research which is conducted on investing the tourism industry and the hotel design criteria. Moreover, the field study is also conducted such as the related photographs. It's also tried to find the existing samples around the world by looking up in the internet. Based on the information, the library and field studies, some criteria are determined for design and led to the final plan.

\section{THE GEOGRAPHICAL LOCATION OF BANDAR ABBAS CITY}


Bandar Abbas is the center of Hormozgan province in south of Iran. It has $27316 \mathrm{Km}$ width (Iran's statistics center, 2006). It's in north of Hormoz neck, in 27 degree and 11 minutes of northern width and in 56 degree and 17 minutes of the eastern out of Greenwich's half a day. It has a variable weather. In the mountain area, it's hot and dry and in the plain areas, it's hot and humid. In the shore area, the weather is very hot and humid in summer and it's temperate in winter. Summer continues 9 months in that place and little by little the hot weather decreases by October. The northern winds are along with dust and an intense humidity which causes a very hot and humid weather which is called "muggy" (Mirkazemian et al, 2007).

The weather in Bandar Abbas city (southern beach) includes a high humid weather, high temperature, sea breeze to the dry area and the local winds. (figure 1)

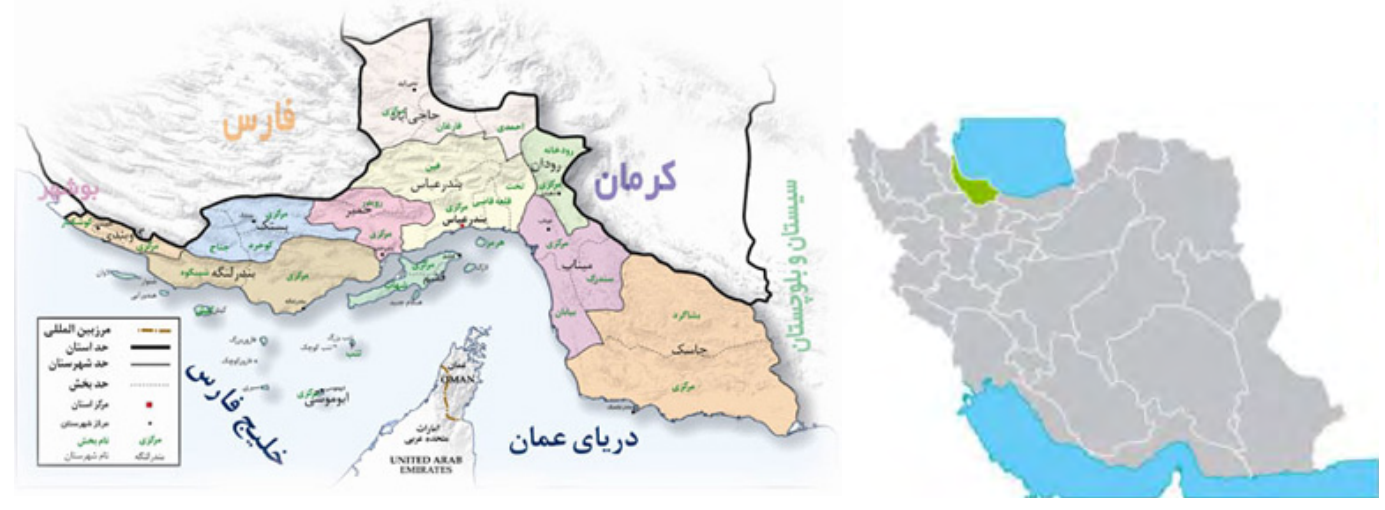

Figure 1. The location of Bandar Abbas city in Hormozgan province and Iran

\section{DEFINITION OF THE HOTEL}

As a whole perspective, hotel is a resort for travelers who aimed at visiting the historical, natural and art attraction or trade around the hotel. There are services at that place such as pool, restaurant, amphitheater and etc. the history of hotel is backed to the big civilizations. In Iran, Mesopotamia and ancient Rome are domination of today's hotels. The word of "hotel" has a French root and it refers to an "urban house" or a place where people mostly visit.

One of the properties of hotels specially the big ones is their self-sufficiency. Today, people have more financial facilities than before but they have less time for relaxation leisure. Therefore, hotels should deliver the maximum services as fast as possible. Moreover, the aesthetic aspect of hotels are also important.

\section{HOTEL GRADES}

The increase of environmental damages and growth of market's demand for green hotels created a new touchstone for grading the hotels. As a result, the first comprehensive guidelines of the world green hotels has entered to the tourist market. Today, there are lots of different hotels around the world which cannot be categorized simply. The hotel grading is based on the beauty and quality of service they offer which increases the rent of rooms. Big rooms with fabulous buildings decorations and expensive sofas reveal the high investment, depreciation, tax and bills. These high costs are compensated by increasing the room prices. Hotels are divided in three main groups in terms of the whole quality:

a. The economic hotels with simple rooms and services for travelers with a limited budget.

b. The trade hotels with high standards and services such as fast internet, laundry service, delivering newspaper in rooms, refrigerator, safe deposit, restaurant and transportation to airport. 
c. The luxury hotels with special architecture and decorations, great restaurants, all room services, pool, massage, spa and etc.

The hotel industry is very variable and complex. It's varied from the luxury hotels to motels with limited services.
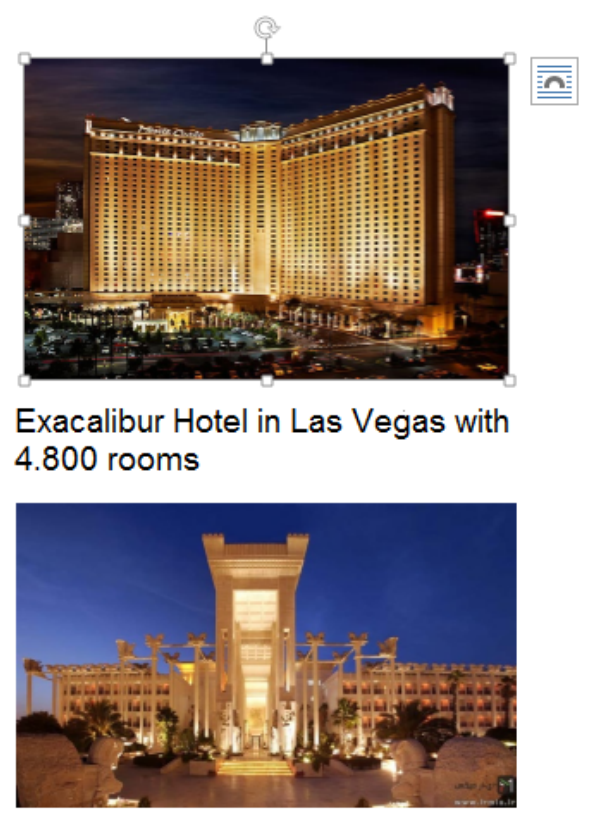

Kadoos Hotel in Rasht

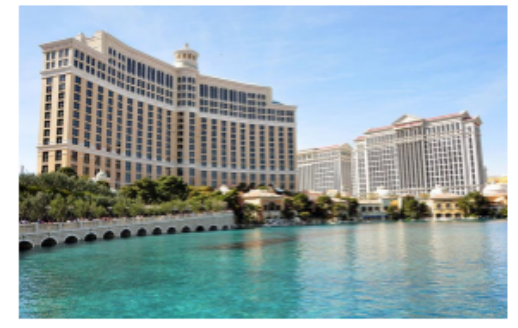

Mont Carlo Hotel in Las Vegas with 3.200 rooms

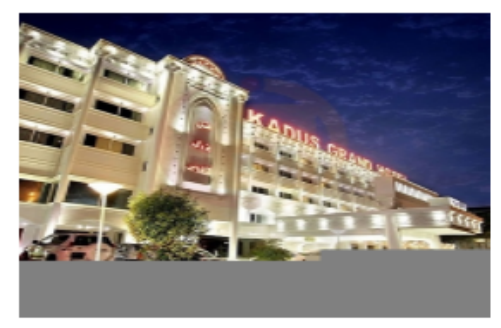

Dariush Hotel in Kish Island

\section{THE PRINCIPLES OF SUSTAINABLE ARCHITECTURE (GREEN)}

The green design is a method for solving the problems that the natural resources are minimally damaged in the process of building. Moreover, in this regard, the materials should be useful and have a life time quality which can be returned to the nature. The life time materials are effective and they are a big block against dissipation and damages. It's better to use them than recycling and use them afterward.

\section{THE ENERGY PROTECTION PRINCIPLE}

Each building should be designed and built in a way that does not need the fossil fuel. The necessary of accepting this principle in ancient time is undeniable. Maybe, because of varieties of new materials and new technologies caused us forgetting this principle. By using different materials and mixing them, buildings change the environment based on user's needs. Pointing to the complex living theory is also useful. It's derived from providing a shelter against cold weather of a cool place for people. This and other reasons led people build their buildings near each other due to many benefits. Buildings which are created in relation to the local climate for decreasing the dependence to fossil fuel have some special experiences comparing to today's normal apartments. Therefore, they are suggested as half way efforts for making green architecture. Many of such experiences are the outcome of individual efforts and it's clear that they are not included in recent buildings and designs as a sustainable principle (the architect's community around different environmental subjects).

\section{WORKING WITH CLIMATE PRINCIPLE}

Buildings should be designed in a way that can use climate and local energy. The shape, position of the building and the location of the interior spaces should be in a way that increase the comfort and decrease the fossil fuel consumption through the correct insulation of the structures. These two procedures have 
different overlaps and same points. Wood has been the main source of energy before the spread of fossil fuel. It still supplies today's 15\% energy. When wood became rare, it was obvious for many people to use solar energy. Cities in Greece like Pyrenees changed their location in a way that avoid flood and they built a rectangular shaped network with eastern-western streets which led them use the sunlight. The Romans also followed the solar design by using the Greece experiences. However, they used crystal windows (which was the innovation after the $\mathrm{f} 1^{\text {st }}$ century) for increasing warmth. The lack of wood as a fuel made the front view of the rich people's house and bathhouses to be built southward. The tradition of design based on the climate is not limited to warmth rules. Architects had to design a cool climate in buildings for a favorable situation. The usual solution of recent era, i.e. using the ventilation systems is not favorable in relation to the climate. It consumes a lot of energy and it's an incorrect way even when energy is cheap and abundant (America's green building council).

\section{THE PRINCIPLE OF DECREASE USE OF NEW RESOURCES}

Every building should be designed in a way that minimizes the use of new resources and creates new resources for other structures during its useful life. Although the approach of this principle is like other principles toward new buildings but it should be mentioned that the most available resources in the world are used in current artifact environment and the improvement of current buildings for decreasing the environment risks is as important as creating new structures. It should be noted that there are not enough resources in the world to be used for recreation of each building. In this way, when reaching to new resources is minimized, then some ways are created so that the one-purpose buildings can be used for other purposes. However, some essential changes can lead to the main changes in the form of building. This might be a disaster for those concerned about the building's permanent maintenance and the question might be arises is that whether a building should be remained unchangeable since it had effective application or some urgent changes should be done for its efficacy or usage. A green procedure might judge this only based on the available resources. If the required resources for changing a building are less that those required for destruction and recreation, such changes should be welcomed. However, this issue does not deny or dishonor the historical importance of the structures. Moreover, these structures may have other values that should be taken into consideration. These problems are revealed differently in changes of the available buildings in order to prepare them according to new needs especially regarding the building's improvement in case of performance and efficacy that may leads to change in their form. Changes in some old buildings can have especial costs and problems. However, the benefit of using such big buildings around each other and in the center of the city can avoid such problems and costs. Recreation of the available buildings in big and small cities can protect the resources in order to destruct and recreation of the building and consequently, it can avoid the society destruction (American council of architectures for different environmental subjects).

\section{HONORING THE USER PRINCIPLE}

The green architecture honors all people use the building. It seems that this principle has a little connection with the pollution caused by changes of the world climate and Ozone layer but the green architecture which honors all common resources in building a complete building, does not exclude human being out of this. All buildings are created by humans but in some, the truth of human presence is honored but in the other, the human presence is tried to be ignored in the process. In Japan, robots are replaced by the human role in creating and designing the buildings but, the efficiency of a project done by a robot includes a special role which can be repeated again and again. However, human can trust his own skills for doing many unrelated tasks. More honor toward the human needs and work force can be examined in two separate ways. For a proficient architect, the safety of resources, materials and process of building is as important as it is for the workers, users and the whole society. Architects are informed about different risks in building sites. Recently, using insulator material (type CFC) or other dangerous materials are forbidden. The positive involvement of the users in the process of building and design is another type of human's cooperation that should be taken into consideration. If they are not properly used, an efficient 
resource is forfeited. Many buildings used this energy and the result led to satisfaction in creating big buildings (count Lebs, 2002).

\section{PRINCIPLE OF HONORING SITE}

Every building should softy and gently touch the earth. Glenn Murcutt, an Australian architect suggested this strange sentence: "each building should softly and gently touch the earth." This sentence suggests an interaction between the building and site which is necessary for the green procedure. It surely has more widespread qualities. A building which greedily consumes energy can cause pollution and it's exotic to users. Consequently, it won't touch the earth gently and softly. It can be explained that no building can be removed out of its root and the previous situation cannot be resurrected in the site. This type of interaction with site can be perceived in desert Arabs. The softness and peace of touching the ground among them was not only hidden in their relocation but also included their materials and assets. The tent they used were made of goat sheep and camel's hair. They were strong against the heavy winds by creating an efficient aerodynamic ground level. They were tightened by long ropes and few poles were used in it because woods are very rare in plains. Though urban communities have left their traditional life style and architects have emerged into design era, still, the temporary structures are needed for creating different exhibitions and cultural activities. Such structures often take forms of desert tents (America's green building council).

\section{HOLISTIC PRINCIPLE}

All green principles requires cooperation in a holistic procedure in order to create the artificial environment. Finding buildings that have all green architectural principles is not simple because the green architecture is not identified completely. A green architecture should include more than a single building i.e. it should include a sustainable form of an urban environment. City is far from sets of buildings. In fact, it can be seen as a set of interacting system (systems for life and recreation) which have a body and by a precise looking to these systems, we can draw tomorrow's future of the city (Count Lebz, 2002).

\section{SUSTAINABLE HOTELS, TOURISM SUSTAINABLE DEVELOPMENT}

Hotel industry as one of the main part of travel of the recent year, tried to apply some sets of activities as environmental management in order to protect the environment. Due to the fact that protecting environment is one of the necessities of the world, then environment management is important in achieving the tourism sustainable development. Sustainable hotel management plays an important role in decreasing negative consequences on environment (by maintaining balance between environmental, social, economic aspects of hotel management) because it uses the energy of water and earth and primer material. Therefore, it produces sewage, wastes and etc. sustainable development means maintaining balance between the development and environment. Today, sustainable development category have important environmental, social and economic impacts on tourism development plan. Tourism sustainable development includes two aspects of environmental and cultural heritage protection.

\section{GREEN HOTELS}

Green hotel refers to single or chain hotels that have more adaptability toward environment and their activities have rare negative impacts on environment.

The process of changing into an eco-Hotel (green hotel) respectively includes:

-

environment

$\bullet$

$\bullet$

trainings to employees for their cooperation
Recruiting experts in the domain of

Establishing an environment committee

Analyzing the hotel's status quo

Providing efficient plans and necessary 
implementation and resolving the weak points

$\bullet$

recycle)

-

$\bullet$

$\bullet$

\section{CONCLUSIONS}

A comparative example has been analyzed in the present research and all sustainable dimensions were perceived in it. However, there's no necessity for all disciplines of sustainable development in landscape. A whole definition for sustainable landscape can be suggested: "a significant relationship between the environment and the addressee that can have unclear future."

If this balance is needed for each of these sustainable dimensions, we have to observe them. It's possible that one of these factors is more important than the others. For example, the landscape is mainly depends to social factors but we cannot ignore the role of other dimensions because the sustainable development cannot be analyzed from one dimensions and other factors cannot be insignificant.

Green buildings are those have little negative impacts on environment. Architects should try to use people's taste in designing the green buildings.

\section{REFERENCES}

Mirkazemian, M., Botorab, S., Fetovat Roodsari, H., (2007), Geotourism Atlas of Hormozgan province, author of geology and mine explorations, national base of country's geology.

Seflayi, f., (2006), city building architecture and a category called sustainable development.

American institute of architecture's council in different environmental subjects

Count Lebz, Watson., D, (2002), climate design of theoretical and implemental principles of energy usage in buildings, Translated by: Ghobadian, V., Feyz Mahdavi, M.

Our journal (Iran's architecture), Vol 12,13, journal related to landscape 